East African Journal of Science, Technology and Innovation, Vol. 2 (3): June 2021

This article is licensed under a Creative Commons license, Attribution 4.0 International (CC BY 4.0)

\title{
Comparative Analysis of Biotechnology Policies and Biosafety Regulatory Regime in the Eastern Africa Countries
}

\author{
${ }^{1 *}$ MUGIIRA, R B
}

1*National Commission for Science, Technology and Innovation of Kenya

*Corresponding author: roybmugiira@gmail.com

\begin{abstract}
Building a vibrant bio-economy enterprise in the East African region, requires facilitative policies and regulatory regimes that allow for the development and application of bio-based technologies in the national production systems. Modern biotechnology, the ability to transfer genes from one organism to another, across species barriers and resulting in genetically modified organisms (GMOs), is a critical technological tool in the sustainable exploitation of genetic resources. The Eastern Africa States are at various stages in the development of biotechnology policies and biosafety regulatory frameworks for the governance of modern biotechnology in response to the global biosafety regulatory instrument, the Cartagena Protocol on Biosafety $(\mathrm{CPB})$. This variance presents a hindrance in the countries' full application of modern biotechnology, thereby limiting their ability to effectively participate in the global bio-economy enterprise. A desk analysis methodology was applied to review information available in the public domain as regards the status of biotechnology policies and biosafety regulatory regimes in eight Eastern Africa countries. The objective of the analysis was to assess their readiness to harness modern biotechnology and generate policy advisory to facilitate the development and application of modern biotechnology. The overall impression of the biotechnology policies and biosafety regulatory regimes in the region is generally restrictive. There is a ban on the importation of genetically modified food in Kenya, a moratorium on the same in Rwanda, strict liability in Tanzania and varying degrees of precautionary overtones in policy statements in some of the other countries. A recent review of restrictive provisions of biosafety laws in Ethiopia and biosafety regulations in Tanzania has allow the commercial growing of genetically modified crops (Bt. Cotton) and conduct of confined field trials research on GMOs, respectively.
\end{abstract}

Keywords: Modern biotechnology; biosafety regulatory framework

Cite as: Mugiira, (2021). Comparative Analysis of Biotechnology Policies and Biosafety Regulatory Regime in the Eastern Africa Countries. East African Journal of Science, Technology and Innovation 2(3). $\begin{array}{ll}\text { Received: } & 13 / 11 / 21 \\ \text { Accepted: } & 09 / 06 / 21 \\ \text { Published: } & 25 / 06 / 21\end{array}$

\section{Introduction}

\section{The Advent of Modern Biotechnology}

The exploitation of genetic makeup of plants and animals is a key pillar in the development of the global bio-economy enterprise. This has been driven, over millennia, by breeding, selection and domestication of these plants and animals. The advent of modern biotechnology through genetic modification (genetic engineering) of plant and animal genomes in the early seventies, greatly enhanced the ability of scientists to manipulate these genomes to achieve diverse objectives $(\mathrm{Au}$, 2015). Effectively, the possibility of transferring genetic material/information/traits across species barriers became a reality, resulting in 
what is commonly referred to as Genetically Modified Organisms (GMOs) or Living Modified Organisms (LMOs).

\section{Global Governance of Modern Biotechnology}

Concerned over the safety of the new science (genetic modification technology) to human and animal health as well as the environment, the global community negotiated and adopted the Cartagena Protocol on Biosafety (Secretariat of the Convention on Biological Diversity, 2000) under the Convention on Biological Diversity (United Nations, 1992). Later the Nagoya-Kuala Lumpur Supplementary Protocol on Liability and Redress to the Cartagena Protocol on Biosafety was negotiated and adopted in 2012. The supplementary protocol addresses issues of apportioning liability and seeking redress in the event of violation of the Protocol through a nonstrict, fault-based regime.

Following its entry into force, State Parties to the $\mathrm{CPB}$ embarked on the development of national biosafety frameworks by publishing policy, regulatory regimes and institutional arrangements to domesticate the Protocol. Many African State Parties adopted an extreme precautionary approach in their biosafety regulatory regimes in line with the Protocol's basic principle and the model biosafety law that was sponsored by the African Union (African Union, 2003).

\section{Status of Adoption (Cultivation) of Biotech Crops in Africa}

The adoption of modern biotechnology in agriculture by cultivation of genetically modified crop varieties (biotech crops) is used in this paper as a yardstick for the global status on the application of modern biotechnology. The cumulative global adoption (cultivation) of Genetically Modified (GM) crops (also referred to as biotech crops) stand at 2.5 billion hectares in 70 countries (including 44 countries that approved importation of GM crop products) (ISAAA, 2018: Figure 1).

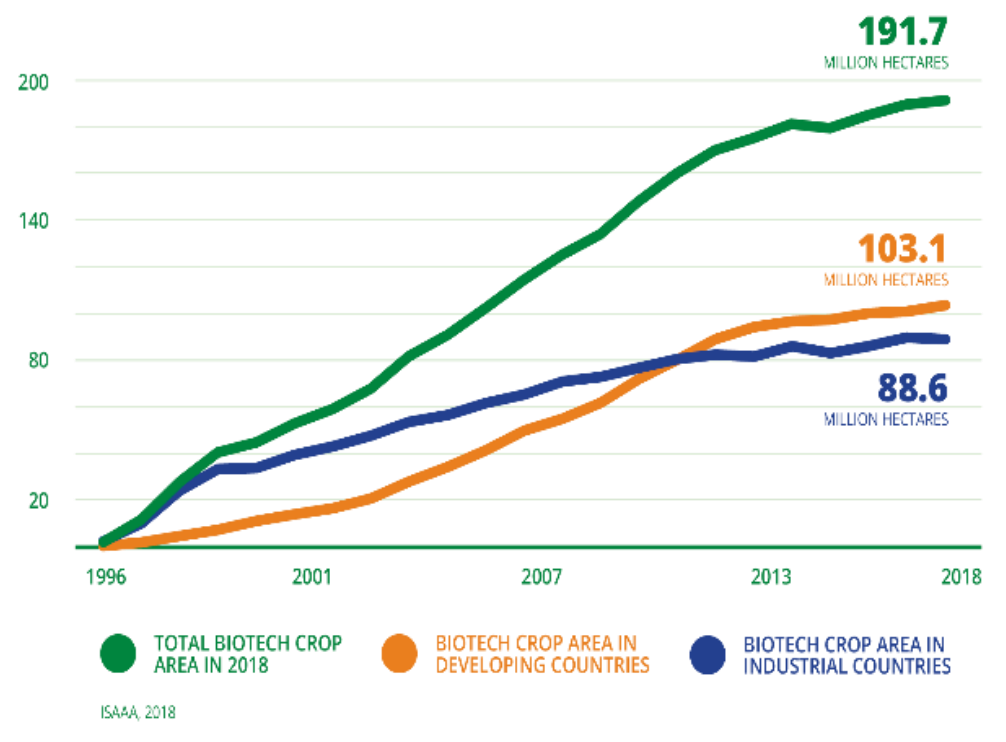

54\% DEVELOPING COUNTRIES AND 46\% INDUSTRIAL COUNTRIES

Figure 1. Global adoption of GM crops in Million Hectares from 1996 to 2018: Industrial and Developing Countries (Source ISAAA Brief 2018) 


\section{Recent Progress Towards}

Adoption of Modern Biotechnology in Africa Nigeria approved biotech cowpea while the kingdom of eSwatini (formerly Swaziland) started commercial planting of Bt. Cotton, making it the third African country to plant biotech crops. This brought the number of African countries currently growing biotech crops to 3 (South Africa), Sudan and eSwatini. Two more countries, (Ethiopia and Nigeria) gave environmental release approvals. Earlier, Kenya and Malawi also granted environmental release approvals and are working towards commercialization of Bt. cotton in the short-term (Figure 2).

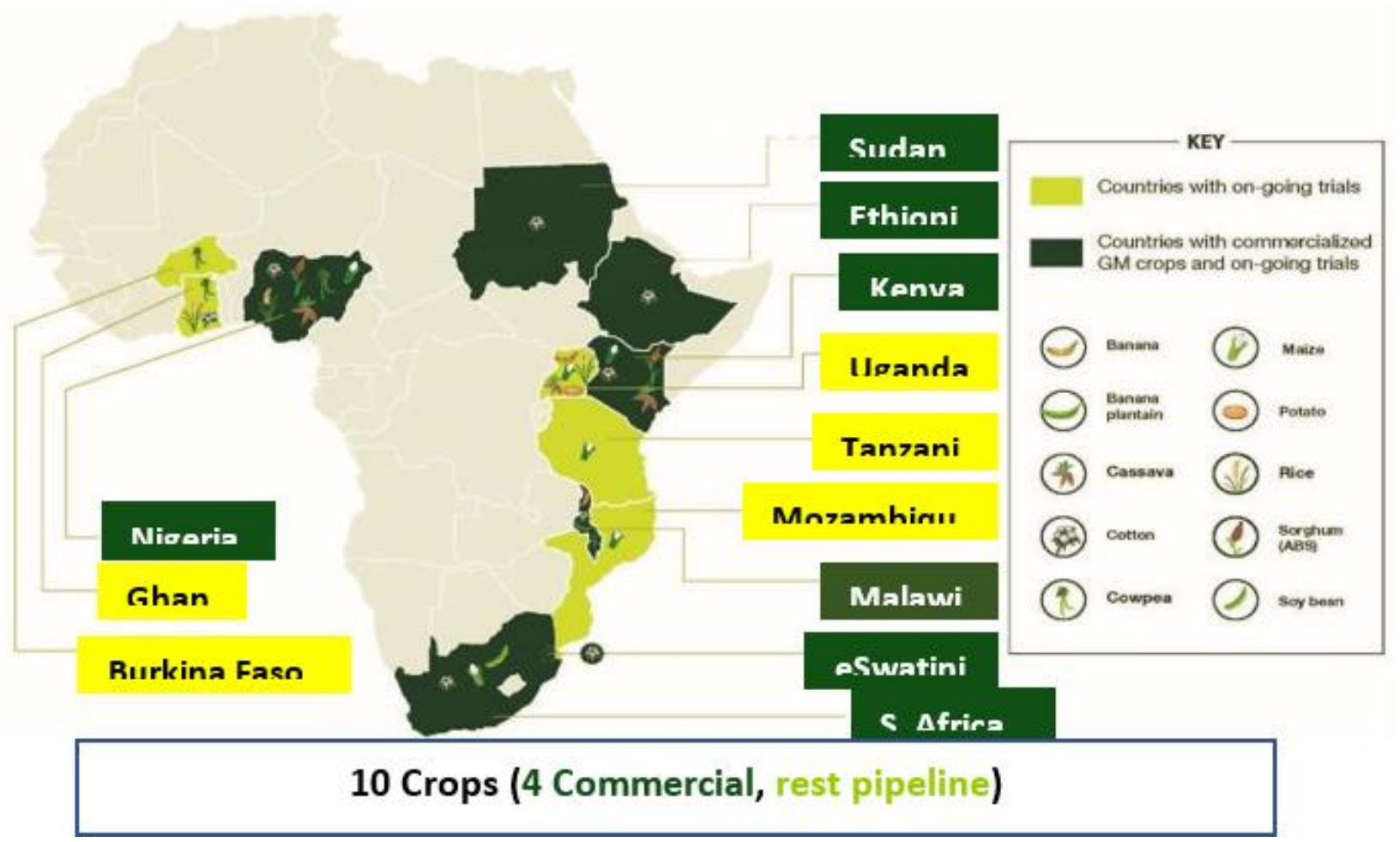

Figure 2. African 2019 Biotech Status: Adoption of GM Crops

On recognizing the potential of modern biotechnology to contribute to economic development, several African States have revised (or are in the process of revising) their biotechnology policies and biosafety regulatory frameworks to allow the development and adoption of modern biotechnology in their productive systems, especially agriculture production to assure food and nutrition security. The African Union Commission (AUC) and the Regional Economic Communities (RECs) are leading in this endeavor with a view to responding to the objective of the African Continental Free Trade Agreement (AfCFTA:
African Union, 2018) of removing tariff and nontariff barriers to intra-African trade.

At the East African Community (EAC), the East African Science and Technology Commission (EASTECO) is leading the development of a regional Bio-economy Strategy to facilitate the sustainable utilization of the region's bioresources. The development and adoption of modern biotechnology is critical in the knowledge-based approach to the exploitation of the region's bioresources. In this regard, a robust and facilitative biotechnology development policy and biosafety regulatory framework across 
the region is essential to the realization of the objectives of the regional bio-economy strategy.

This paper presents a comparative analysis of the biotechnology development policies and biosafety regulatory regimes in the EAC Partner States with the view of assessing the region's preparedness to fully integrate into the global bio-economy enterprise. The analysis of the Ethiopia and Sudan policies and regimes is also presented to provide a complete picture of the Eastern Africa Region. These two States are considered to be progressing well in the review of their biosafety regulatory frameworks leading up to the subsequent adoption of modern biotechnology in the production of the cotton variety that is genetically modified (Bt. Cotton) to resist the destructive cotton ball worm.

\section{Materials and Methods}

The analysis was conducted through desk reviews of Biotechnology policies and Biosafety laws, decrees, proclamations and regulations in EAC Partner States to identify gaps and flag out specific provisions that may present restrictions to the development and application of modern biotechnology. An attempt was made to give an overview of the policy and regulatory landscapes in each EAC Partner State based on information in the public domain.

The reviews also included two non-EAC Partner States (Ethiopia and Sudan) that have reviewed their Biotechnology policies and Biosafety regulatory regimes and subsequently approved the cultivation of the biotech cotton variety (Bt. Cotton). This will provide important leaning points for EAC Partner States that are in the process of developing or reviewing their biotechnology policies and biosafety regulatory regimes to facilitate the adoption of modern biotechnology.

Basic conclusions have been drawn from analysis of the reviews and presented as clear policy advisory notes for policy makers within the Eastern Africa Region to consider a facilitative policy and regulatory framework for the application of modern biotechnology. Ultimately, this is expected to pave the way for the full integration of the region into the global bioeconomy enterprise.

\section{Results}

Generally, biotechnology policies (written or pronounced) and the biosafety regulatory regime in Africa has been cited as a major hindrance to the continent's desire to tap on the enormous benefits of modern biotechnology (Chambers, 2013, Nan'gayo, et al., 2014). The participation of Africa in the global biotechnology enterprise and international biosafety negotiations under the $\mathrm{CPB}$ is still below the continent's potential (Karembu, et al., 2015). A number of publications point at policy review requirements for the continent to effectively integrate into the global biotechnology enterprise (Mugiira \& Miano 2015, Fagerström, et al., 2016, Juma \& Serageldin 2007).

Additionally, the African Union Commission (AUC) and Regional Economic Communities have initiated programmes geared towards the harmonization of biotechnology policies and biosafety regulatory regimes as well as capacity building for effective biosafety regulation (Waithaka, et al., 2015). These programmes, will greatly enhance the integration of the continent into the global biotechnology enterprise and contribute to the objective of the African Continental Free Trade Agreement (AfCFTA) by removing non-tariff barriers to intra-continental trade (African Union 2018). The results of an analysis of biotechnology development policies and biosafety regulatory regimes of the Eastern Africa region is presented in a country-bycountry basis.

\section{Biotechnology Development Policies and Biosafety Regulatory Framework in Burundi} The republic of Burundi is signatory to the Cartagena Protocol on Biosafety and has initiated the process of ratifying the Nagoya Kuala Lumpur Protocol. Burundi developed the National Biosafety Framework in 2007, named the National Strategy and Action Plan on Biological Diversity (SNPA-DB). Biotechnology policy and biosafety regulatory framework is not yet operational in Burundi. In this regard, Burundi is neither equipped with a clear biotechnology policy or a specific Biosafety regulation.

The overall objective of SNPA-DB is stated as: 'promoting the development of modern biotechnology around a participative Biosafety system' and calls for 
the 'Promotion of biotechnologies that support the improvement and maintenance of biodiversity'. The Action Plan recognizes that Burundi may find it beneficial to engage in biotechnology research and further outlines measures 'To encourage the industrial research in Biotechnology'.

The term GMO does not appear in any legal or regulatory text applicable in Burundi. However, the country has developed a draft bill on Biosafety. The aim of the bill is to establish procedures for safe development and handling of Genetically Modified Organism (GMO) to ensure safety of human health and the environment. The demands of safeguarding the genetic identity of seeds, plants and crop products, which is the closest provision for Biosafety regulation is enforced under the law number 1/ 010 of June 30, 2000 on the Environment Code. The law provides for a joint analysis of new animal and plant species by the Minister in charge of the Environment and the Minister in charge of Agriculture and Animal Husbandry, prior to their introduction into the country to ensure that their proliferation do not harm the population of indigenous species or disrupt natural balances.

The regulatory agency for Biosafety in Burundi is the Ministry of Environment. There is no publicly declared policy on imports or exports of commodities with GM content. The World Food Programme (WFP) and other relief agencies import relief food commodities, which may contain GM content into the country. Due to lack of a declared policy or law on importation of food commodities with GM content, such relief food is not regulated in any special way.

The SNPA-DB is supportive of Biotechnology development and application but is also laced with the usual 'precautionary' expressions that characterize the rallying call of the Cartagena Protocol on Biosafety and other Biosafety regulatory provisions of a host of other African countries as derived from the African Model Law.

These applicable Biosafety laws/decrees in Burundi do not provide for the specific requirements of governing the development and application of modern biotechnology (specifically genetic modification-GM technology) or the engagement in trade with commodities with GM content. The laws/decrees have no basis on the global instrument for the governance of modern biotechnology namely the Cartagena Protocol on Biosafety. The draft Biosafety Bill is not available in the public domain as it is still work in progress.

Biotechnology Development Policies and Biosafety Regulatory Framework in Kenya

Kenya developed the National Biosafety Framework with the support of the UNEP/GEF project leading to the publication of the National Biotechnology Development Policy in 2006. This was spearheaded by the National Council for Science and Technology (NCST), under the Ministry of Higher Education, Science and Technology. The Kenya National Biotechnology Development Policy is supportive of harnessing modern biotechnology for the country's socioeconomic development as demonstrated by the following policy statements expressions:

"The Government recognized the role Biotechnology can play in poverty reduction, enhancing food security, and in the conservation of biodiversity and the environment".

"The Government will, as a matter of priority, initiate appropriate steps to explore the use of biotechnology for the benefit of Kenyans and, furthermore, ensure that Kenya becomes a key participant in the international biotechnology enterprise within a decade...."

"......this will be pursued through the provision of an enabling environment that responds to the needs of the biotechnology industry, the research and development communities as well as relevant national and international biosafety concerns".

Kenya has a comprehensive biosafety regulatory regime with a Biosafety Act of 2009 that establishes the National Biosafety Authority and a set of four implementing regulations namely, The Biosafety (Contained Use) Regulations; The Biosafety (Environmental Release) Regulations; The Biosafety (Export, Import and Transit) Regulation; and The Biosafety (Labeling) Regulations.

Kenya's biosafety regulatory regime has kept very close fidelity to the Protocol in terms of legal provisions and provided reasonably workable procedures for applications in the various categories of activities under regulation. However, at enforcement of the law, there is a very weak coordination between the various regulatory agencies identified in the Act. 
Further, certain provisions of the biosafety law and its implementing regulations present obstacles that may not be of biosafety nature. These include: hefty penalties of up to twenty million Kenya shillings and/or imprisonment in contravention of the law; high fees charged on applications; long time frame of decision-making on applications; overlaps on risk assessment requirements of the Environment Management and Coordination Act (EMCA) under the National Environment Management Authority (NEMA) and the Biosafety Act under the National Biosafety Authority (NBA); the Biosafety (Labeling) regulations present a stringent low-level allowance of less than 1\% presence of GM content.

The most formidable obstacle to all engagements in modern biotechnology in Kenya is the ban on importation of GM food that was imposed by the Cabinet in October 2012. This presents great challenges given that Kenya is a transit country for many Countries in the East African region and is also home to many refugees, who regularly receive food aid supplies. Shipments of commodities with GM content are allowed through the Kenyan territory as long as evidence of approval in the receiving State is presented to the NBA.

Despite the ban, the Cabinet approved the commercial growing of GM (Bt.) cotton to contribute to the revitalization of the cottontextile-apparel, food (oil) and feed (cotton seed cake) value chains. This is expected to support the Government's food/nutrition security and manufacturing components of the 'Big Four' Agenda.

\section{Biotechnology Development Policies and Biosafety Regulatory Framework in Rwanda}

The republic of Rwanda developed the National Biosafety Framework in 2008 with support from UNEP-GEF project implemented by the Rwanda Environment Authority under the Ministry of Natural Resources. The National Biosafety policy covers human resource capacity development, biotechnology financing, commercialization, institutional frameworks, and implementation of the Cartagena Protocol on Biosafety to which Rwanda is signatory.
A Biosafety Bill that has been drafted pursuant to the provisions of the Organic Law on Environment is awaiting approval by Parliament to become law. The bill proposes Rwanda Environment Management Authority (REMA), within the Ministry of Natural Resources as the National Competent Authority with the office of Registrar within REMA being the National Focal Point for the Protocol. The bill also proposes relevant institutional and National Biosafety Committees to advice the Registrar. However, even as the bill undergoes further processing to become law, the declared policy is that officially, GM imports are not allowed in Rwanda.

This policy applies to both emergency food aid and commercial imports of GM commodities in the country. The country does not officially allow transit of GM products through its territory whether milled or not, nor does it authorize supply of food with GM content to refugee camps in the Country. This undermines the positive development proposals espoused in the National Biotechnology Policy and goes against the tenets of the Protocol to which Rwanda is signatory. Further, the position puts into jeopardy the process of developing a sound biosafety regulatory regime.

Biotechnology Development Policies and Biosafety Regulatory Framework in South Sudan According to records available in the Biosafety Clearing House $(\mathrm{BCH})$ of the $\mathrm{CBD}$, the Republic of South Sudan has identified the Deputy Director for Wetlands and Biodiversity in the Ministry of Environment and Forestry as the National Focal Point. There is not much more information available on the biotechnology policies and biosafety regulatory regime of South Sudan. This can be attributed to the fact that the country is relatively young in terms of institutional establishment.

Biotechnology Development Policies and Biosafety Regulatory Framework in Tanzania The Tanzania biosafety guidelines (2009) are based on the National Environmental Management Act, 2004 addressing the movement, use and commercial application of GMOs and their products. The Tanzania biosafety regulation apply three main principles namely, the precautionary principle - approval or refusal should depend on clear scientific 
knowledge and lack of such knowledge shall not be used as a basis for not taking preventive measures; the prevention principle - risk assessment and environmental impact assessment to be carried out so that informed decisions may be made; the principle of strict liability - any party, individual or corporate that deals with the introduction of a GMO or its products shall be liable for any harm, injury or loss caused directly or indirectly by those GMOs and their products or any activity related.

The liability clause further states that "In case of harm to the environment or to biological diversity, redress shall include the costs of clean up and rehabilitation whether incurred or to be incurred and costs of any preventive measures to follow, to the satisfaction of the national biosafety focal point". An individual or any legal person have the right to seek redress in respect of breach or threatened breach of the (biosafety) regulations. Such persons shall not be expected to pay costs even if their action failed, if it was out of reasonable concern.

Under socio-economic, cultural and ethical considerations, the Tanzania biosafety guidelines cover a wide range of safety and non-safety issues which are relevant for general release of GMOs and their products. Issues related to intellectual property rights (IPR) such as patenting biotechnology innovations, protection of indigenous varieties and undisclosed traditional knowledge and biodiversity; implications of crossing with local varieties (GMOs contaminations), customer choices and contradictions to religious beliefs are highlighted.

The key lesson learnt from the Tanzania biosafety regulation regime is that inclusion of 'products' and the adoption of precautionary and prevention principles coupled with strict liability that extends to individuals dealing with the introduction of GMO is a powerful disincentive to any entity intending to engage in the biotechnology enterprise. The result of this provision is the reluctance of potential biotechnology development agents and partners to deal with any biotechnology activity in Tanzania. Indeed, the country was initially left out of the Water Efficient Maize for Africa (WEMA) Project, a potentially beneficial Public-
Private-Partnership before embarking on a review of some of the restrictive provisions.

The Nagoya-Kuala Lumpur Supplementary Protocol on Liability and Redress adopted an administrative fault-based liability regime as opposed to the strict liability regime. Countries (Party States) that adopt a strict liability regime in their biosafety regulatory framework are therefore in contravention of the provisions of the Supplementary Protocol. Such biosafety legal provisions do not serve the respective Party States well as they can be challenged in an international arbitration process.

\section{Biotechnology Development Policies and Biosafety Regulatory Framework in Uganda} Uganda developed the National Biotechnology and Biosafety policy in 2008 through the Uganda National Council for Science and Technology (UNCST) under the Ministry of Finance, Planning and Economic Development serving as the National Competent Authority. The policy provides a framework for safe application of biotechnology in order to contribute to Uganda's economic growth and transformation in line with the national Vision 2025. In this regard, the policy is supportive of the development and application of modern biotechnology for the country's socioeconomic development as demonstrated by the following statement in the foreword to the policy by the Minister:

"........ aspects of Biotechnology applied in genetic engineering that involves transferring useful genes, such as those that confer disease resistance or tolerance to drought, across species resulting in genetically modified organisms (GMOs) is relatively new. This new aspect of biotechnology creates enormous opportunities for agricultural modernization, industrial production and environmental protection. Application of modern biotechnology can therefore, be very instrumental in realizing Uganda's development potential, especially in agriculture, health and environment management".

To implement the policy, a Biosafety Bill has been drafted, which is undergoing Parliamentary processing. The bill is well in line with the provisions of the Protocol and establishes an overall framework for regulation of GMOs in Uganda with the UNCST designated as the National Competent Authority. In the absence of a law, Uganda has been operating under interim 
arrangement supported by the Science and Technology Act Cap 209, under which guidelines and standard operating procedures for overseeing research were developed. This has enabled the Country to undertake a number of confined field trials of transgenic crops as well as laboratory experimentation.

A Presidential Commission Report published in 2003 recommended that GM imports into the Country should be approved by the UNCST and be in milled form. The Commission called for the expeditious development of the biosafety law. The current arrangements have facilitated the country to received GM food aid imported from the United States of America through several humanitarian agencies. The Ugandan system is therefore adequate for humanitarian food aid and confined field trials but requires a law on biosafety to make it comprehensive and facilitate commercial growing of GM crops.

Biotechnology Development Policies and Biosafety Regulatory Framework in Ethiopia Ethiopia ratified the Cartagena Protocol on Biosafety in September, 2009 and benefited from the UNEP-GEF grant to develop the National Biosafety Framework and capacity building. The Biosafety Proclamation No. 655/2009 is Ethiopia's biosafety law. The law is based on the precautionary principle and makes many provisions that are very stringent, exceeding those of the Protocol. Some of these provisions cannot be fulfilled by applicants, thereby rendering the emerged biosafety regime unworkable (Adane, 2013).

In recognition of these limitations and the great desire for Ethiopia to tap onto the benefits of modern biotechnology (GM technology), the country initiated a process to review the Proclamation by addressing the obstacles to the development and application of modern biotechnology. The review process has resulted in the amendments contained in the Biosafety (Amendment) Proclamation No. 896/2015, published on 14th August, 2015.

Some of the compelling factors for the adoption of GM technology in Ethiopia are the Country's Growth and Transformation Plan (GTP) and the strategic importance of Cotton in Ethiopia's economy. To support the textile sector, the GTP envisaged the need to focus on cotton production among other crops and to triple the contribution of the sector to the GDP by 2015. Stakeholders are in agreement that this can only be achieved by increasing production efficiency and minimizing losses caused by pests and diseases by applying GM technology.

In general terms, the Biosafety (Amendment) Proclamation No. 896/2015 is a great step towards making the Ethiopian Biosafety Regulatory regime workable and fairly conducive to the development of Modern Biotechnology, especially within research and confined field trials (contained use). The review of definitions and insertion of new ones, including "Modern Biotechnology, Contained Use" and the additional provision for a "Special Permit" specifically for contained use go a long way to offer clarity of purpose and objective of the Proclamation.

However, as expressed below, the amendment did little to address the specific provisions that were deemed to be disincentive to the private sector, development partners and biotechnology service providers to engage in the commercial biotechnology enterprise in Ethiopia. Further, more work remains to amend/review the various Directives to conform to the amendments in the Biosafety (Amendment) Proclamation No. $896 / 2015$. This has been undertaken in earnest and allowed the cultivation of GM (Bt.) cotton, currently undergoing National Performance Trails (NPTs).

Biotechnology Development Policies and Biosafety Regulatory Framework in Sudan Sudan established a National Biosafety Framework in 2010 with the support of the UNEP-GEF project. The framework establishes the National Biosafety Council under the Ministry of Environment. Technical matters of the Council are handled by a National Biosafety Technical Committee with experts from relevant ministries.

Sudan does not have a stand-alone policy for Biotechnology and Biosafety but enacted the Biosafety Law in 2010. The scope of the law is to regulate GMOs in contained use, GMOs for food and feed including food aid, GMOs release into the environment, as well as GMOs for pharmaceutical use. The stated aim of the 
Biosafety law is to enable Sudan to benefit from Biotechnology outcomes and to protect humans and the environment against any potential risks that may arise from GMOs.

The narrative within the Sudan Biosafety Framework document and the Biosafety Law including public pronouncements by leaders in the country can be described as being facilitative of the development and application of modern biotechnology. Sudan is the fourth Country in Africa after South Africa, Egypt and Burkina Faso to commercialize a GM crop (Bt. Cotton) through a collaborative project with the Chinese Government implemented by the Biotechnology and Biosafety Research Center of the Agricultural Research Corporation. This is a perfect example of a working collaboration or partnership led by a local institution thereby marshaling the much needed domestic public support.

\section{Discussion}

Genetic modification of plants and animals, through the application of modern biotechnology has emerged as a critical technological tool in the sustainable exploitation of genetic resources. The technology offers almost unlimited possibilities in the enhancement of agricultural productivity for food and nutritional security as well as protection of the environment. This highly regulated technology has remained out of reach of African farmers due to restrictive and inhibitive policies and regulatory frameworks adopted by majority of African States. Africa therefore, just like in the case of the green revolution, has been left behind by the rest of the world in the adoption of modern biotechnology and left to play catch-up role. As this is going on, newer and more versatile biotechnologies such as genome editing and synthetic biology are taking root in other parts of the world.

Currently, the main applications of modern biotechnology in agriculture are designed to overcome both biotic and abiotic constraints to production, and to enhance the nutritive value of crop plants. These traits are of significant importance to Africa given the continent's predisposition to biotic and abiotic stresses and chronic food deficit or nutritional deficiency.

\section{References}

The East African Community has embarked on the development of a regional bioeconomy strategy to facilitate the sustainable exploitation of bioresources. The success of the strategy is pegged to a regional biotechnology development policy and biosafety regulatory environment that is sufficiently robust for the facilitative development and application of modern biotechnology. The great disparity in the level of biotechnology policy and biosafety regulatory framework within the Eastern Africa countries is a major disincentive to investment in biotechnology enterprise in the region and presents a form of a non-tariff barrier to intraregional trade. A review and harmonization of these policies and regulatory frameworks is of the essence if the region is to effectively participate in the global bioeconomy enterprise.

\section{Conclusion}

The biotechnology policy environment and the biosafety regulatory regimes in the Eastern Africa region are not sufficiently robust or facilitative for the development and application of modern biotechnology for socio-economic development. The Ethiopian case is a valuable lesson for the countries in the region on efforts to review restrictive legal provision to facilitate the development and application of modern biotechnology.

\section{Recommendations}

For the countries in the region to effectively and sustainably tap on their enormous bio/genetic resources in the evolving global bio-economy enterprise, they will need to:

1. Develop policy and regulatory framework in line with the $\mathrm{CPB}$ and with a view to facilitating the application of modern biotechnology in their productive systems;

2. Lift blanket bans and handle the application of various biotechnologies on a case-by-case basis; and

3. Review restrictive provisions in their biosafety regulatory system in view of existing scientific evidence on the safety of biotech products.

Adane, A. (2013): Toward a Workable Biosafety System for Regulating Genetically 
Modified Organisms in Ethiopia: Balancing Conservation and Competitiveness. Pubmed 4(1): pp 28-35. doi: 10.4161/gmcr.24375.

African Union (2003) Executive Council Decision on the Report of the Interim Chairperson on the Africa-Wide Capacity Building in Biosafety Doc. EX/CL/31(III).

African Union (2018) African Continental Free Trade Area: Creating One African Market. Kigali, Rwanda.

$\mathrm{Au}$ R. (2015) From Genetic Engineering to Genome Engineering: What Impact has it made to Science and Society? Advances in Biology, Biotechnology and Genetics 2(1) pp 1-8.

Fagerström T., Mugiira, R. B. and Forsse L. S. (2016). Biotechnology: the tool Africa cannot afford to ignore. The African Technopolitan, African Center for Technology Studies. Nairobi, Kenya.

ISAAA (2018). global status of commercialized biotech/gm crops in 2018: biotech crops continue to address the challenges of increased population and climate change. ISAAA Brief (54).

James C. (2018) Global Status of Commercialized Biotech/GM crops: 2013. ISAAA Brief No. 46. ISAAA Ithaca, NY.

Juma C. and Serageldin I. (2007) Freedom to Innovate: Biotechnology in Africa's Development'. A Report of High-Level African Panel on Modern Biotechnology. African Union (AU) and Partnership for African Development (NEPAD). Addis Ababa and Pretoria.

Karembu, M., Mugiira R.B., F. Nguthi and P. Chege (2015) Enhancing Africa's Capacity for Global Engagement in International Biosafety Negotiations. Africa Agri-Biotech Updates. Issue Brief 6.

Mugiira, R. B. and Miano D. (Edts) (2015). Harnessing Agricultural Biotechnology for Africa's Economic Development: recommendations for policy makers. Network of African Science Academies (NASAC), Nairobi, Kenya.

Nan'gayo, F., Wafukho S. S. and Oikeh, S. O. (2014): Regulatory challenges for GM crops in developing economies: The African experience. Transgenic Research.
Springer International Publishing Switzerland.

Secretariat of the Convention on Biological Diversity (2000). Cartagena Protocol on Biosafety to the Convention on Biological Diversity: Text and Annexes. Montreal: Secretariat of the Convention on Biological Diversity.

United Nations (1992) Convention on Biological Diversity.

Waithaka M, Belay G, Kyotalimye M and Karembu M (2015) Progress and challenges for Implementation of the Common Market for Eastern and Southern Africa Policy on Biotechnology and Biosafety. Front. Bioeng. Biotechnol. 3:109. doi: 10.3389/fbioe.2015.00109. 